\title{
Examining International Students' Attitudinal Learning in a Higher Education Course on Cultural and Language Learning
}

\author{
William R. Watson \\ Sunnie Lee Watson \\ Sarah E. Fehrman \\ Purdue University, USA \\ Ji Hyun Yu \\ University of Michigan, USA \\ Shamila Janakiraman \\ Purdue University, USA
}

\begin{abstract}
This study examined students' perceptions of attitudinal learning outcomes and instructional activities within a language and cultural exchange (LACE) course at a midwestern U.S. university and explored whether perceptions differed based on students' prior knowledge, major, and/or demographics. We utilized a mixedmethods approach to gather quantitative data from a survey sent out in Weeks 5 and 15 to 137 international students enrolled in multiple sections of a LACE course that gathered perceptions on attitudinal learning and the most impactful aspects of the course design. Follow-up structured interviews were conducted with 37 students. Results indicated students saw growth in their attitudinal learning, with the highest perceived gains regarding cognitive and then behavioral components. Data from student interviews provided specific examples of how student attitudes were changed in each of these four areas of learning. Limitations and future research are discussed.
\end{abstract}

Keywords: attitude change, attitudinal learning, cultural learning, higher education, international students, language learning 
Language and cultural exchange (LACE; Allen \& Fehrman, 2018) courses utilize an English as a Second Language (ESL) curriculum that balances language and culture by focusing on language-mediated intercultural activities to develop "several types of expertise, including complex understanding of cultural differences (cognitive dimension), capacity to accept and not feel threatened by cultural differences (intrapersonal dimension), and capacity to function interdependently with diverse others" (King \& Baxter Magolda, 2005, p. 574). The LACE curriculum goes beyond traditional ESL curriculum by helping students work toward language fluency and sociocultural adjustment in an American academic context using a variety of methods, including field trips, active learning, storytelling, reflection, forming relationships with other students from diverse backgrounds, and participating in mentoring with LACE instructors (Allen \& Fehrman, 2018). LACE courses focus primarily on undergraduate international students, who report higher levels of stress and depression than graduate international students ( $\mathrm{Li}$ et al., 2013). This study explores how well a LACE course was able to facilitate this kind of sociocultural adjustment, defined as "the ability to 'fit in,' to acquire culturally appropriate skills, and to negotiate interactive aspects of the host environment" (Brunsting et al., 2018, p. 23) for first-year international students by promoting positive attitude change.

International students must navigate many invisible barriers and unspoken expectations, but they often don't recognize these barriers before crashing into them, so LACE courses prioritize affective and behavioral skills and the cultural and contextual knowledge needed to navigate the variety of social and academic situations they will encounter as international students. This kind of development is characterized by seeing different cultural perspectives and engaging with ideas and people different from the student's own cultural/linguistic background (Noddings, 2005, 2010; Rifkin, 2009). Students also participate in intergroup dialog to build relationships with people from other groups and explore similarities and differences across cultures (Nagda \& Gurin, 2007).

The purpose of this study was to examine LACE students' perceptions of attitudinal learning outcomes and instructional activities within the course. In addition, we explored whether students' perceptions of attitudinal learning differ based on their prior knowledge, major, and/or demographics.

\section{LITERATURE REVIEW}

As the numbers of international undergraduate students enrolled in American universities have increased, researchers have turned their attention to the unique needs of this student population and what factors predict or account for successful sociocultural adjustment. There are four broad themes that have emerged across the literature: English proficiency, intercultural competence, social support, and faculty relationships.

\section{English Proficiency}

The great majority of researchers identify English proficiency as a key factor in sociocultural adjustment to the American academic context. Specific areas such as 
lecture comprehension (Andrade, 2010; Andrade \& Evans, 2009) or academic vocabulary (Andrade et al., 2014) were identified, as well as general English language proficiency (Brunsting et al., 2018; Han et al., 2017; Zhang \& Goodson, 2011). These researchers all found that increased levels of English proficiency negatively predicted acculturative stress. Only one researcher, Bai (2016), concluded that English was not a significant predictor of acculturative stress. In addition to greater sociocultural adjustment, increased English proficiency has been linked to higher grade point averages (Martirosyan et al., 2015), lower levels of depression (Smiljanic, 2017), and greater integration and community with domestic students and faculty members (Trice, 2007). Furthermore, students with lower levels of English are less likely to seek out help when they need it (Li et al., 2016).

\section{Intercultural Competence}

A second compelling predictor of successful sociocultural adjustment is increased intercultural competence. There is a consensus that intercultural competence is essential, but less consensus about what, why, or how intercultural competence influences international students (Deardorff, 2015). Researchers have identified a number of ways to measure and address the culture component, including levels of homesickness (Andrade et al., 2014), acculturation (Zhang \& Goodson, 2011), cultural intelligence (Mesidor \& Sly, 2016), acculturation strategies (Brunsting et al., 2018), and cultural assimilation (Li et al., 2013). Several studies, including those of Li et al. (2013) and Brunsting et al. (2018), identified the cultural component as the strongest predictor of sociocultural adjustment and overall wellbeing. Increased intercultural competence can lead to better academic performance (Young \& Schartner, 2014). Glass (2012) recommended courses focused on intercultural conversations and including cultural activities outside the classroom. These kinds of cross-cultural interactions lead to increased cross-cultural awareness and complexity of thought (Engberg \& Mayhew, 2007), which are essential components for future social and academic success (Korobova \& Starobin, 2015; Lowinger et al., 2016). Engaging with students and ideas from different cultural backgrounds, even in informal interactions (Pike \& Kuh, 2006), leads to an increase in students' awareness of their own culture and values, greater comfort when interacting with a wide variety of people (Glass, 2012), and fitting into the campus culture (Kovtun, 2011).

\section{Social Support}

Having a strong social support system is another predictor for sociocultural adjustment. Zhang and Goodson (2011) reviewed the literature and concluded that social support was one of a few factors most essential for international students to develop a sense of belonging in the United States. Mesidor and Sly's (2016) later review concurred. Van Horne et al. (2018) reported that international students felt less of a sense of belonging than their domestic peers and that social interaction was a significant predictor of belonging. It is important for international students to socialize with other international students, and students experience greater social 
support when they are friends with other international students instead of exclusively with American students (Chavajay, 2013; Poyrazli et al., 2004). Other benefits to social support include diminishing feelings of depression and perceived discrimination (Jung et al., 2007)), higher levels of participation in extracurricular activities (Gómez et al., 2014), and lowered stress levels among international students (Baba \& Hosoda, 2014). Friendship, social support, social interaction, and belonging are also essential for successful sociocultural adjustment (Brunsting et al., 2018).

\section{Faculty Relationships}

One surprising theme that has emerged from the literature is the importance of student-faculty interactions, beyond general social interaction. Previous researchers have found students who feel connected to faculty and instructors are more likely to persist in their studies (Anaya \& Cole, 2001; Frost, 1991; Kuh \& Hu, 2001; Terenzini \& Pascarella, 1980). Other predictors of successful sociocultural adjustment have included understanding American classroom interaction patterns (Andrade et al., 2014), feeling attached to a particular professor (Han et al., 2017), and receiving instruction on normal social and academic behavior in an American context (Brunsting et al., 2018). A sense of belonging is crucial to sociocultural adjustment. Perceived university support (Bai, 2016) and increased interaction/relationship with faculty (Han et al., 2017; Longerbeam et al., 2013) help increase international student feelings of belonging. The presence of interactions or relationships with faculty alone wasn't enough to promote sociocultural adjustment. Faculty who were able to help students have conversations with students from diverse backgrounds (Glass, 2012) or provide students with opportunities to reflect on their transitional experience (Kovtun, 2011) were especially effective.

There is a need to develop courses that promote English language fluency, increase intercultural competence, equip students to build relationships with people of dissimilar backgrounds, and provide opportunities for students to have meaningful interactions with faculty. However, very little research has been done on courses like this (Mori, 2000; Zhao et al., 2005). Research has not kept pace with the needs of international students (Brunsting et al., 2018), and there is a "lack of data regarding how specific academic activities facilitate international students' successful transition to the United States" (Kovtun, 2011, p. 350).

One way to achieve these outcomes is to develop courses that move beyond simply providing international students with new knowledge and instead focus on changing their behaviors and attitudes. This approach can equip these students with the means to succeed within the culture and context of an American university.

\section{Attitude and Attitude Change}

According to Gagne et al. (1992), attitude refers to the psychological evaluations a person has about an object, person, or event and is comprised of cognitive, affective, and behavioral components (Kamradt \& Kamradt, 1999). Additionally, the important role that social interaction, including interaction with peers, plays in shaping attitudes 
(Kamradt \& Kamradt, 1999; Simonson \& Maushak, 1996) highlights social learning as a core strategy for promoting attitudinal learning (Watson et al., 2018).

The goal of attitudinal instruction is to influence learners' attitudes and behaviors to better align with the target attitude (Coleman, 2010; Mueller et al., 2017). Mueller et al. (2017) argued that a sound instructional design principle for promoting attitudinal learning is instruction that targets all the components of attitude. To implement this effectively, attitudinal instruction should encompass a variety of activities that not only provide knowledge about the topic but also encourage reflection and action.

Providing new information that targets the cognitive component of attitude (Bodenhausen \& Gawronski, 2013) and creates cognitive dissonance (Festinger, 1962) results in a mind receptive to attitude change. This can be facilitated by providing emotionally provocative content that addresses the affective component (Kamradt \& Kamradt, 1999; Simonson, 1979). To address the behavioral component, learners should be encouraged to perform an action slightly inconsistent with their existing attitude and slightly consistent with the target attitude (Kamradt \& Kamradt, 1999). This is not always easy because learners' pre-existing beliefs hinder changes in attitude (Sinatra et al., 2012) and also influence learning outcomes (Dole \& Sinatra, 1998). Placing learners in authentic situations to produce a sense of empathy toward people or objects (Ascione, 1992) and encouraging critical reflection practices (Ligon et al., 2009) can promote affective and behavioral changes in attitude. Interacting with peers through the sharing of attitudes (Kamradt \& Kamradt, 1999; Kort et al., 2001), discussion (Dole \& Sinatra, 1998), and collaboration while applying the target attitude (Kamradt \& Kamradt, 1999; Simonson \& Maushak, 1996) have been recommended as social learning strategies for promoting attitude change. These strategies echo the four key factors for successful international undergraduate sociocultural adjustment with exercises targeting the cognitive skills and knowledge of English proficiency and intercultural competence, the behaviors of practicing and applying such skills and knowledge, the affective confidence and emotional intelligence that comes with contextual and cultural understanding, and the social learning that takes place with a focus on social support and faculty relationships.

\section{Purpose of the Study}

This study examines a course designed to positively impact international students' attitudes in order to increase the likelihood of their success at an American university. In this study, we will seek to answer the following questions:

- Research Question 1: What are the students' perceptions of attitudinal learning outcomes (cognitive, affective, behavior, and social) within the course?

- Research Question 2: Do students' perceptions of attitudinal learning differ based on their prior knowledge, major, and/or demographics? 
- Research Question 3: What are students' perceptions of instructional activities within the course? What course successes and challenges do the students identify?

\section{METHOD}

To examine the three research questions, we used a convergent parallel mixedmethods design, where qualitative and quantitative data are collected and analyzed separately, and then merged (Creswell \& Plano Clark, 2011). Figure A1 (see Appendix) illustrates the overall design of the study. First we collected quantitative data to examine student perceptions of attitudinal learning, their preferred instructional activities' impact on their attitudinal learning, and if learning was impacted by gender, age, or ethnicity. We also collected qualitative data to investigate how students perceived instructional activities impacted their learning. We obtained Institutional Review Board approval prior to conducting the study.

\section{Study Participants}

Participants included 137 international undergraduate students from 18 countries enrolled in a Fall 2017 semester of a LACE course at a large Midwestern U.S. university (see Table A1 in Appendix). The course included 3 hours of instruction each week divided into three 50-minute classes or two 75-minute classes each week for 16 weeks. The majority of participants were Asian (80.3\%), studying natural sciences $(59.1 \%)$ or social sciences $(25.5 \%)$. The gender distribution was almost equal with $72(52.5 \%)$ males. On a scale from 1 to 5 (with 1 being extremely low and 5 being extremely high), students' precourse ratings of perceived prior knowledge averaged 3.18 (i.e., "one sample question"). Thirty-seven students responded to the interview invitation.

\section{Data Sources and Procedures}

In order to assess students' perceptions of attitudinal learning gains, we utilized the Attitudinal Learning Inventory (ALI; Watson et al., 2018) to survey students at two different points in the course. We emailed surveys at Week 5 (early survey) and Week 15 (late survey) to all enrolled students to see how their perceptions on attitudinal learning progressed throughout the semester. The validated instrument examines attitude as comprised of four components (cognitive, affective, behavioral, and social) through a total of 15 items, utilizing a 5-point Likert scale $(1=$ strongly disagree, 5 = strongly agree). The Cronbach alpha was .92, demonstrating good internal consistency (see Table A2 in Appendix).

For qualitative data, we attended two LACE instructor meetings and class sessions during the semester. In addition, we sent interview invitation emails to all LACE course students 16 weeks after the course conclusion to gather interview data on how the students felt the course impacted them after the conclusion of the course. The structured interview asked eight questions (see Table A3 in Appendix). 


\section{Data Analysis}

For analyzing quantitative data, we investigated relationships between perceived level of prior knowledge and attitudinal learning gains using Pearson productmoment correlation coefficient. To analyze data and address the specific research questions related to differences by gender, major, and time, we performed repeated measures multivariate analyses of variance (MANOVAs).

For qualitative data analysis, we coded interview transcriptions and field notes using open and focused coding techniques for emerging patterns (Miles et al., 2013). We grouped repeated incidents in the data from coding into categories for emergent themes. We then categorized responses to specific interview questions related to attitude change, success, and instructional methods into predefined groups. We constantly compared of codes from the interview and field notes from instructor meetings and classroom observations in order to achieve data triangulation (Hine, 2000). Finally, we also followed up with peer debriefing and member-checking procedures with the instructors in order to verify analysis results (Schwandt, 2014).

\section{Course Description}

The LACE course is a foundational class for international students who have learned English as a second language and is part of an instructional and assessment program that helps international students develop the academic, linguistic, and cultural competencies needed to succeed in college life. Course objectives are to facilitate students' ability to (a) speak English more fluently; (b) read English more fluently; (c) communicate in English with increased clarity; and (d) develop and apply a process for cross-cultural comparison and reflection. The course prioritizes both language and culture objectives, and this current study focuses on the fourth objective. This process for comparison and reflection enables students to recognize internal cultural biases, identify other perspectives, and shift their own perspective and attitude to better navigate cross-cultural interactions. First-year international students are automatically enrolled in this course at this large Midwestern university based on their English language proficiency test scores.

The university's LACE Program provides rubrics and assignment guidelines to all instructors across all sections to ensure program and curricular fidelity. This allows for reasonable certainty that all material is delivered as planned across multiple sections with multiple instructors.

The course is divided into three units, and the first unit, called "Self-Regulated Language Learning," focuses on time management, personal learning responsibility, and setting effective (SMART) goals. The final project for unit 1 asks students to reflect on all the topics they have studied so far and choose one topic to write about in a reflection paper.

Unit 2 is titled "Experiential Learning in Your Context" and largely focuses on intercultural learning and academic integrity in an American context. Instructional topics include reading fluency and two intercultural frameworks - the cultural iceberg model and the Describe Analyze and Evaluate (DAE) framework-for better understanding experiences. The unit also covers stereotypes and generalizations, 
citation and plagiarism, group work and collaboration, an individual field trip, unspoken expectations, and email communication. For the final unit project, students go on a field trip to learn something about American culture, and write a reflection and record a presentation about their field trip experience.

Unit 3 is titled "Telling My Story" and focuses on dealing with culture shock, personality, and different types of holiday traditions. The final project is a video presentation, a short in-class summary presentation, and a written reflection regarding what personal growth the students perceived during the course.

\section{RESULTS}

Research Question 1: What are the students' perceptions of attitudinal learning outcomes (cognitive, affective, behavioral, \& social) within the course?

\section{Cognitive Learning}

Student interview and survey responses indicated a number of impacts from the course that align with cognitive learning outcomes in such areas as improved time management, self-regulation, study, writing, and speaking skills; improved understanding of American culture, stereotypes of America, how to deal with culture shock; and how to apply the DAE framework. The ALI results for cognitive learning also showed that students agreed with statements pertaining to cognitive attitudinal learning throughout the course (see Table 1).

Table 1: Student Perceptions of Attitudinal Learning $(N=137)$

\begin{tabular}{lcc}
\hline Variable & $M$ & $S D$ \\
\hline Cognitive Learning Week 5 & 4.05 & 0.85 \\
Cognitive Learning Week 15 & 4.16 & 0.80 \\
Affective Learning Week 5 & 3.69 & 0.93 \\
Affective Learning Week 15 & 3.71 & 1.02 \\
Behavioral Learning Week 5 & 3.77 & 0.89 \\
Behavioral Learning Week 15 & 3.91 & 0.91 \\
Social Learning Week 5 & 3.68 & 0.79 \\
Social Learning Week 15 & 3.76 & 0.86 \\
\hline
\end{tabular}

\section{Understanding Self-Regulation and Time Management}

Numerous students reported that they recognized the improvements they made with self-regulation and time management skills after taking the class, as well as how to better study and communicate in both written and spoken English. Students described how they expected the class to focus on their English speaking and writing but they were surprised at how much more the course covered and the instructional strategies. Students described initial disappointment at having to take the course, but after realizing its benefits and how its scope went beyond the English language, they were grateful for how it helped them to succeed as college students. They mentioned 
the course helped them to be better at managing their time and regulating their learning, as Hua described: "The self-regulated learning and time management really helped me during the first month when I'm still not familiar with the life [at college]."

While students had expected to learn how to better use English, their interviews also revealed other cognitive elements of how their attitude changed beyond learning to better communicate, study, and self-regulate. Students noticed attitude changes regarding American culture, stereotypes regarding Americans, and how to deal with culture shock living at an American university, including the use of the DAE framework.

\section{Understanding American Culture and Stereotypes}

Numerous students highlighted the benefits of the course's focus on culture as key to their attitude changes. As international students, the majority of them were living in the United States for the first time. A commonly repeated theme was the role that movies and other American entertainment media played in shaping their prior understanding of American culture, including cultural stereotypes. For example, Yao's statement that he "learned most of the knowledge about American culture by watching American TV shows" was echoed by several other students. It was clear that media had promoted stereotypes of Americans, often negative ones, as Lorenzo, observed: "I had just a lot of prejudices and stereotypes toward the American culture."

Beyond recognizing that their stereotypes of Americans and American culture were incorrect, the course also helped them to gain a better understanding of what American culture was like. This cultural understanding not only represented a positive affective attitude toward Americans but also a cognitive componentknowledge, regarding commonly held American values. Viola illustrated this point with very specific details regarding some of the cultural components that had been learned from the class:

Some of the things that I did not know before coming here about American culture were their views about their society. For example, individualism vs collectivism, equality vs hierarchy, meritocracy vs ascription... and many more. All these ideas were very new to me especially because in most of them my country has the opposite view on them, so learning about this was very helpful.

This specific understanding of American culture and the breaking of stereotypes also helped students to fight against feelings of culture shock that could arise from living in America for the first time. Jing described how the course helped with her hurt feelings toward her American roommate:

My roommate is an American, and she never interacts with me.... At first, I thought that she was really cold and bad. But after I learned about the value 'individualism', I knew that her behavior was actually part of the American values. Americans tend to treat roommate just roommate, but not friend. 


\section{The DAE Framework}

Finally, many students cited the DAE framework from the course as a helpful strategy in navigating the often jarring situations of their cross-cultural adjustment. Lorenzo noted:

I stopped making judgments only by seeing what I only see, I try to go beyond, I try to give a reason to everything, in a certain sense I started using the DAE cycle in a lot of different situations.

Apart from changing perspective and attitudes toward stereotypes regarding Americans, a number of students noted that they applied what they learned to also disrupt prior conceptions they had of various cultures, as well as races and genders.

Affective Learning. One area that students demonstrated attitudinal change was in their affective learning. There were indications of increased confidence and positivity related to English language use, college life, and more openness to American culture. Similarly, many students noted a reduction in their fear and nervousness related to these issues. The ALI results for affective learning also showed that students agreed with statements pertaining to affective attitudinal learning throughout the course, although not as strongly as cognitive outcomes.

\section{Feeling Confident with English Communication as a College Student}

A clear theme the students described was gaining increased confidence from the course. The practice of giving course presentations and speaking in class with their international peers, as well as the frequent writing practice, helped them be more confident in their other courses in addition to just living as a college student in America. As Woo illustrated:

After taking the... class, I found the English writing is not that hard anymore. I can write some journals and essays quickly and fluently. Also, my group members are more relaxed when giving me writing tasks, even in some specialized courses. These changes really build up my confidence.

This increased confidence was also related to the students' ability to navigate American college life, not simply their level of comfort with English. Quan described how interactions with her instructor helped her to feel more confident in speaking to her professors:

I used to be a person that do not like to talk to teacher. In my mind I think teacher is higher status than students. However, in the class, my professor like to talk joke to students and she shows she is equal to us. I begin to like to talk and share idea in class.

Students also highlighted how their increase in confidence helped them socially, as they were more confident in approaching and speaking to American students, as Jun highlighted: 
I was really shy and I thought that Americans are different and they are superior to me so I was always hesitant to talk to them. But after... [course activities] I figured that they are same people as me and they are always welcome for us to be friends with them.

\section{Feeling Positive and Open-Minded with American College Culture}

In related results, students reported feeling more positive, comfortable, and openminded regarding American and college culture and how to interact with Americans. A common theme among students was how the course helped them to understand American culture and how Americans communicate, which helped prevent misunderstandings and increase their confidence in communicating with Americans. As an example, Lilah provided an example of how the course helped with communication and confidence with group work in other courses:

...when I was doing my engineering group project, one of my groupmates... always said things that I think sounded so hostile towards me. After knowing that most American speak their thoughts directly, I learned that I shouldn't pay too much attention... he said such things to other people in my group too and they all responded directly to him just like what he did to us.

These international students were facing the challenge of having to adapt to education in a second language, while also adapting to an unfamiliar culture and learning to be college students for the first time. The course targeted strategies and information to help students address each of these challenges, and the students noted how the course helped them to adapt. As Daeyeoul put it, "My mind and attitude that were related to college were totally changed. Adapting to college was a whole new problem, and the class helped me with that a lot."

\section{Feeling Less Nervous and Fearful}

As these students have illustrated, there are challenges on multiple fronts that must be faced simultaneously while students are adapting to life at an American university. They described how these LACE courses increased their confidence, reduced their fear and nervousness, and ultimately, increased their happiness. In highlighting what aspect of the course was most impactful, Mei recognized the value of class materials and activities in helping her overcome her culture shock:

Before...I feel pointless and loneliness when I am alone. I do not know what to do or what should I do, I am helpless. After I got the information related with culture shock in...class, I learned about it. I followed the guide I get in book and in class material. Things get better after that.

Other students also spoke to how increased confidence helped them to adapt to life at an American university and feel more comfortable and ultimately happier. Wu 
commented on the power in the combination of language and culture instruction and activities:

I have been more confident for living in the United States.... I love the feeling of getting [along] well with my American classmates and finally become friends with them. In summary, I have a sense of happiness for staying [at this college].

Behavioral Learning. Behavioral outcomes are particularly of interest given they are often the focus of efforts to change attitude (Jaccard \& Blanton, 2005), and are also indicative of the interrelated nature of attitudinal components. These outcomes often arise as a result of positive impacts on other attitudinal components, such as new cognitive knowledge or intense feelings. Students described behavioral changes related to their openness to speaking with Americans, being more expressive when communicating, and managing time and energy better. The ALI results for behavioral learning showed students agreed with statements pertaining to behavioral attitudinal learning throughout the course, more strongly than affective but less strongly than cognitive outcomes.

\section{Talking with Americans and Using Expressive Communication}

Students not only felt more confidence in speaking with Americans but put it into action by following through. Students guessed their behavior was possibly due to increased confidence in their English language skills as well as a better cultural understanding of Americans. Jun who had gone to an American high school wrote:

I struggled from a low self-esteem, but after taking this course I became more outgoing and right now I talk to Americans regularly and I have made new friends.... When I was in high school I used to avoid Americans when they were trying to have conversation with me, but now I don't get scared and join the conversations.

Students were also able to increase their proficiency with nonverbal communication as their confidence and English abilities increased. Viola commented, "Something that I did improve on was physical representation on feedback. That means like nodding, and eye contact when someone is speaking to you or giving a presentation."

\section{Setting Goals for Managing Time and Energy}

Students also highlighted how their behavior changed regarding time management, goal setting, and managing their physical energy. Numerous students benefited in a variety of areas from learning the SMART goals method. As Hui-Chao described, "I learned the concept of SMART goal... Therefore, I spend my time more regularly and manage my time in a scientific way. It helped me study more efficiently and have a healthier body."

These examples clearly show how students took the cognitive knowledge that they gained, a specific goal-setting framework, and applied it to their behavior. The 
result of this application was a positive impact to their college experience, which then improved their confidence and outlook on college.

Social Learning. The ALI results for social learning showed students agreed with statements pertaining to social attitudinal learning throughout the course, very slightly more than with affective learning outcomes.

A common theme that emerged from student comments was the importance of social interaction in attitude change. Social interactions with the instructor increased confidence in speaking with their instructors or asking questions in class, and the required course presentation and regular course discussions helped them gain confidence and shift their attitudes toward American and other unfamiliar cultures. Lorenzo described: "One of the most impactful activities in this class was what we did every day for the entire semester: share our opinion with our classmates that came from all over the world."

\section{Research Question 2: Do students' perceptions of attitudinal learning differ based on their prior knowledge, major, and/or demographics?}

\section{Relationships Between Perceptions of Prior Knowledge and Attitudinal Learning Gains}

We performed preliminary analyses to ensure no violation of the assumptions of normality, linearity, and homoscedasticity. Overall, we found positive correlations between the four dimensions of attitudinal learning, while there were strong, negative correlations between the perceptions of prior knowledge, cognitive learning gains, and affective learning gains (see Table 2).

Table 2: Pearson Correlation Among Prior Knowledge and Attitudinal Learning $(N=137)$

\begin{tabular}{|c|c|c|c|c|c|c|c|c|c|c|c|}
\hline Variable & $M$ & $S D$ & 1 & 2 & 3 & 4 & 5 & 6 & 7 & 8 & 9 \\
\hline PK & 3.18 & 0.86 & - & & & & & & & & \\
\hline CL W5 & 4.05 & 0.85 & -.298 & - & & & & & & & \\
\hline CL W15 & 4.16 & 0.80 & $\begin{array}{c}-.272 \\
* *\end{array}$ & $.566^{* *}$ & - & & & & & & \\
\hline AL W5 & 3.69 & 0.93 & -.260 & $.790^{* *}$ & $.465^{* *}$ & - & & & & & \\
\hline AL W15 & 3.71 & 1.02 & -.201 & $.521^{* *}$ & $.791^{* * *}$ & $.525^{* *}$ & - & & & & \\
\hline BL W5 & 3.77 & 0.89 & -0.13 & $.704^{* *}$ & $.594^{* *}$ & $.642^{* * *}$ & $.568^{* *}$ & - & & & \\
\hline BL W15 & 3.91 & 0.91 & -0.14 & $.576^{* *}$ & $.739^{* *}$ & $.510^{* * *}$ & $.824^{* *}$ & $.617^{* *}$ & - & & \\
\hline SL W5 & 3.68 & 0.79 & -0.02 & $.572^{* *}$ & $.350^{* *}$ & $.589^{* *}$ & $.369^{* *}$ & $.474^{* *}$ & $.346^{* *}$ & - & \\
\hline SL W15 & 3.76 & 0.86 & -0.12 & $.398^{* *}$ & $.662^{* *}$ & $.356^{* *}$ & $.718^{* *}$ & $.471^{* *}$ & $.689^{* *}$ & $.378^{* *}$ & - \\
\hline
\end{tabular}

Note. $\mathrm{PK}=$ prior knowledge; $\mathrm{CL}=$ cognitive learning; $\mathrm{AL}=$ affective learning; $\mathrm{BL}$ $=$ behavioral learning; $\mathrm{SL}=$ social learning. $* * p<.01,{ }^{*} p<.05$ 


\section{Group Differences for Changes in Attitudinal Learning Gains Over Time}

We used a repeated measures MANOVA test to determine whether there was a difference in students' perceptions of attitudinal learning gains in the beginning and end of instruction. The within-group independent factor was time (Week 5, Week 15) and the between-group factors were gender and major. The course was 16 weeks in length, so we used Week 5 to represent early in the course experience, while we chose Week 15 to represent late in the course experience. The dependent variable is the average value of each component in attitudinal learning (cognitive learning, affective learning, behavioral learning, social learning). To examine any violation of the repeated measures MANOVA assumptions, we used Box's test of equality covariance matrices and Levene's test of equality of error variances. Box's test showed a significant value larger than .001 , indicating the assumption of covariance was not violated. Levene's test also revealed equal variances across different groups, showing all the significant values larger than .05. All of the attitudinal learning components were within an acceptable range of the value for skewness and kurtosis between -2 and +2 , indicating no violation of multivariate normality.

The results of our repeated measures MANOVA revealed that there were no significant main effects for either gender or major; however, a significant interaction effect of gender with time $F(4,130)=2.64, p=.037, \eta_{\mathrm{p}}^{2}=.075$ was found (see Table 3).

Table 3: Results of Repeated Measures MANOVA

\begin{tabular}{lcccc}
\hline Variables & $d f$ & $F$ & $p$ & $\eta$ \\
\hline Time & 4 & 1.60 & .178 & .047 \\
Gender & 4 & 1.05 & .385 & .031 \\
Major & 4 & 1.22 & .307 & .036 \\
Time $\times$ Gender & 4 & 2.64 & $.037^{*}$ & .075 \\
Time $\times$ Major & 4 & 1.37 & .249 & .040 \\
Gender $\times$ Major & 4 & .97 & .427 & .029 \\
Time $\times$ Gender $\times$ Major & 8 & .25 & .910 & .008 \\
\hline
\end{tabular}

Note. $* p<.05$

Post hoc analyses revealed that female students showed an increase in their perceptions of affective learning gains: $F(1,133)=3.36, p=.039, \eta_{\mathrm{p}}{ }^{2}=.002$; as well as behavioral learning gains: $F(1,133)=1.11, p=.029, \eta_{\mathrm{p}}{ }^{2}=.027$, while male students were less likely to perceive affective learning gains and behavioral learning gains over time (see Table 3).

Table 3: Means and Standard Deviations of Affective Learning and Behavioral Learning

\begin{tabular}{|c|c|c|c|c|c|c|c|c|}
\hline \multirow{3}{*}{ Variable } & \multicolumn{4}{|c|}{ Affective learning } & \multicolumn{4}{|c|}{ Behavioral learning } \\
\hline & \multicolumn{2}{|c|}{ Week 5} & \multicolumn{2}{|c|}{ Week 15} & \multicolumn{2}{|c|}{ Week 5} & \multicolumn{2}{|c|}{ Week 15} \\
\hline & $M$ & $S D$ & $M$ & $S D$ & $M$ & $S D$ & $M$ & $S D$ \\
\hline
\end{tabular}




\begin{tabular}{lcccccccc}
\hline Female & 3.71 & 0.89 & 3.89 & 0.94 & 3.81 & 0.77 & 4.10 & 0.86 \\
Male & 3.68 & 0.98 & 3.550 & .85 & 3.73 & 0.98 & 3.77 & 0.88 \\
\hline
\end{tabular}

Research Question 3: What are students' perceptions of instructional activities within the course? What course successes and challenges do the students identify?

\section{Instructional Method}

In order to determine students' perceptions of the course activity most impactful to their attitudinal learning, we asked participants to select all that apply from a list of the course activities for the most impactful learning activity. As shown in Figure A2 (see Appendix), students perceived reading the course textbook, working with a partner or the group, and SMART goals as the most effective activities. Overall, the result showed that students valued individual activities (e.g., course reader, selfreflection journal, and writing exercises) more than collaborative activities (e.g., group projects), despite the fact that a number of students interviewed highlighted the positive impact of interaction with their peers and recommended increasing such interaction outside of class. Furthermore, students identified group and partner work as the second most popular instructional activity, so clearly it was still highly valued even if the majority preferred individual activities.

Within the interviews, a number of strategies were highlighted, including the SMART goals, time management curriculum, and frequent writing practice that were already discussed in the cognitive learning section. Additionally, numerous students remarked on the field trips, group discussions and presentations, and the DAE framework as the activities that impacted them the most.

\section{Field Trips}

In the second unit, students were asked to go on a campus field trip to learn about American culture and write and record a video reflection on the experience. Students described a variety of different field trips, including visiting the Black Cultural Center on campus (which many students identified as highly impactful for them) as well as going to campus sporting events and learning the university chants and cheers. Bahar described how beneficial the field trip and the resulting reflections were for a variety of reasons, both academically and personally:

I learned how to research, cite properly, and prepare effective presentations. But most importantly I learned a great deal about friendship and male and female relationships [in] America. Both of these subjects have impacted my life and helped me shape my attitude....

\section{Group Discussions and Presentations}

The course included a great deal of group learning activities, primarily in class discussions, and a significant number of students identified these discussions as very 
impactful for increasing their level of comfort with communicating in English. As Mina described, "Through... [class discussions], we learn how to speak clearly and share our thoughts. This activity will also increase confidence and our fluency in English." Apart from speaking in class during discussions, students were required to film multiple video presentations and give a final presentation in class, which they noted helped them be more confident in speaking in front of others.

\section{DAE Framework}

In addition to other tools, students highlighted the DAE framework as instrumental in their successes in approaching and accepting other cultures and perspectives. Some students felt less anxiety about intercultural interactions and increased willingness to experience new situations. Others identified the framework as helpful in other academic situations; as Fang said, "I love the DAE method, which help me a lot when comes to writing English essays and class discussions."

\section{Recommendations}

Finally, regarding instructional methods and activities, students discussed recommendations for improving the course. Many of these suggestions were to simply increase the amount of time spent on activities the students enjoyed and found beneficial, such as more field trips or increased group work or group activities, including out of class group work. Others focused on broadening the scope of the course and examining world cultures as a more accurate reflection of the multicultural nature of the student body, rather than focusing so narrowly on American culture. Other recommendations included additional English listening practice to improve listening comprehension, incorporating more American entertainment media, given how much students had previously been influenced by it, and more interactive inclass activities such as games and debates.

\section{DISCUSSION}

Results indicated that students were able to notice growth in their own attitudinal learning, with the highest perceived gains regarding cognitive and then behavioral components. Affective and social components were also confirmed but at lower levels. Data from student interviews provided specific examples of how student attitudes were changed in each of these four areas. Students identified cognitive gains in terms of improved English speaking and writing, increased understanding of American and college culture, improved goal setting, time management, and study skills, and specific tools such as the DAE framework. These findings confirm other prior studies on the benefits of cultural exchange or transition courses. These studies have shown student learning gains in academic abilities such as writing and presentation abilities (Kovtun, 2011), as well as cultural knowledge, university expectations, and active learning and group-work strategies (Andrade, 2006).

Students also discussed affective benefits from the course, such as reduced anxiety and increased confidence in such areas as interacting with American students 
in and out of class (Brunsting et al., 2018), confidence interacting with faculty (Andrade, 2009), and being more understanding of cultural differences, a key finding as research has shown that students with higher intercultural competency skills score higher academically (Young \& Schartner, 2014). These examples were also illustrative of the interconnectedness of the attitudinal components described by Kamradt and Kamradt (1999). For example, the behavior changes students noticed often came as a result of students applying the cognitive knowledge they gained from the course. Students reported feelings of increased confidence and decreased anxiety allowed them to more fully participate in and benefit from class activities targeting behavioral learning, such as field trips and class speaking activities. This interrelatedness is an important finding and confirms previous recommendations for attitudinal instruction to target all attitudinal components (Kamradt \& Kamradt, 1999; Mueller et al., 2017).

The fourth component to attitudinal learning, social learning, was also confirmed in student comments. While survey results indicated learning outcomes in this area were rated the lowest, students recommended increasing the number of group activities, both in and outside of class, and described the benefits of class discussions. This echoes prior research showing such courses can benefit students by increasing confidence and knowledge of how to communicate with students of other cultures outside of the classroom (Brunsting et al., 2018). The importance of social aspects of learning to attitude change instruction has been highlighted both theoretically (Kamradt \& Kamradt, 1999), and in prior research (Dole \& Sinatra, 1998; Simonson \& Maushak, 1996; Watson et al., 2017; Young \& Schartner, 2014).

We tracked student perceptions of attitude change over time by gathering perceptions early (in Week 5) and late in the course (at Week 15). Results were consistent, showing growth as a whole but not at a significant rate. Interestingly, when we analyzed results by student demographics, there were no significant differences by gender or major. However, when examining learning over time as it related to gender, the analysis indicated that female students showed significant increases in affective and behavioral learning over time, while males showed significant decreases in the same components. No clarifying research was found in the literature to explain this outcome; however, it could be indicative that while differences in gender were not represented during the course, there could be differences in the long-term transfer of attitudinal learning.

We also examined how student perceptions of attitude change were related to their perceived prior knowledge regarding the topics. The statistical analysis showed a negative relationship between the students' prior knowledge and their perception of both affective and cognitive change. The relationship with cognitive change is not surprising as a student would be likely to learn less new material if they had prior exposure to that material. The relationship with affective change can also be explained given the interrelatedness of the attitudinal components. A student more familiar with American culture, for example, might have less of an emotional response to being exposed to the culture in class. This was reflected in the interview comments as a few students noted having attended an American high school and thus were more familiar with the culture, had American friends, and were more comfortable with the language. Of note is the lack of a relationship between prior 
knowledge and the social and behavioral constructs of attitude. This might indicate that despite prior knowledge, students still perceived that they had implemented positive behaviors and were engaged around the social learning elements of the course.

Finally, the data showed that students found the activities they completed individually to be more impactful than collaborative activities. A few students highlighted social learning as beneficial in their interviews, but as a whole, social learning was ranked lower than both cognitive and behavioral outcomes. One reason for this might have been the more personalized options available to students with the individual activities. For example, the ability to choose one's own field trip allowed for students to pick a topic that they were interested in. Individual activities also allowed for student reflection, as students created individual presentations, kept a journal, and reflected on activities like the field trip as well as the course as a whole and how it had impacted them. This personal sort of reflection is an important aspect of attitude change (Kamradt \& Kamradt, 1999; Mueller et al., 2017) and could explain the student perceptions behind the high impact of individual activities. Ultimately, positive feedback was given for both individual and group activities, and social learning with peers is a key recommendation for designing effective attitudinal instruction in general (Kamradt \& Kamradt, 1999; Watson et al., 2018) and supporting international students specifically given their challenges and need for social support (Mesidor \& Sly, 2016; Zhang \& Goodson, 2011).

There were several limitations to this study that should be considered. We asked students to provide their perceptions of their attitudinal learning in the course and discuss how the course impacted them. While surveys of participant perceptions have an established history in psychology (Bohner \& Dickel, 2011), the study could be strengthened by further measurements that operate outside of participant reflections. While this study represents only individual students at a specific university and was therefore not intended to be generalizable, it provides evidence that targeting international student attitudes beyond a cognitive focus can result in attitude change, including behavioral change.

\section{CONCLUSION}

There are a number of implications of this study to consider. Students reported that they were more confident and comfortable with language, culture, and the context of learning and living at an American university due to the LACE course. Cognitive and behavioral growth were most apparent to the students, while learning was also perceived in affective and social learning. It was clear that these attitudinal components were highly interrelated as students highlighted instances of applying newly gained knowledge to alter their behaviors and experiencing emotional development, such as increased confidence, as a result. These findings indicate the importance of incorporating a variety of targeted attitudinal components, instructional objectives, and assessments in order to increase the likelihood of learning gains rather than focusing solely on traditional cognitive outcomes.

While social learning was the lowest outcome among the components, results indicate the importance of social learning for some students. This implies the 
importance of offering a variety of both individual and group-based activities. By doing this, students gain the opportunity to both practice new cultural and language skills with their peers while also having the ability to have more customized experiences that match better their individual interests and needs. Solitary reflection and practice opportunities also provide a low-pressure environment for skill development.

Finally, the differences in learning among students based on prior knowledge and experience again provides implications for the importance of customizing learning activities to individual students' needs, allowing for more advanced students to focus greater attention on areas of need as opposed to being forced to work at areas that may already be relative strengths. Precourse assessments could allow for student grouping or more personalized learning paths in courses to ensure that students have the greatest opportunity for learning rather than a homogenized curriculum.

Ultimately, beyond adding additional insights to an important topic that has received limited attention in the research, this study has shown the potential benefits of diversifying instructional objectives to incorporate less traditional attitudinal objectives. By incorporating a variety of attitudinal components and moving beyond a sole focus on language, including cultural learning and study skills, international students gain confidence, more quickly feel themselves a part of the community, and are better able to manage their own learning, improving their chances of success.

\section{REFERENCES}

Allen, M. C., \& Fehrman, S. E. (2018). Language and cultural exchange: A guidebook for international students (4th ed.). Van Griner.

Anaya, G., \& Cole, D. G. (2001). Latina/o student achievement: Exploring the influence of student-faculty interactions on college grades. Journal of College Student Development, 42(1), 3-14.

Andrade, M. S. (2006). A first year seminar for international students. Journal of the First-year Experience \& Students in Transition, 18, 85-103.

Andrade, M. S. (2009). The effects of English language proficiency on adjustment to university life. International Multilingual Research Journal, 3(1), 16-34.

Andrade, M. S. (2010). Increasing accountability: Faculty perspectives on the English language competence of nonnative English speakers. Journal of Studies in International Education, 14(3), 221-239.

Andrade, M. S., \& Evans, N. W. (Eds.). (2009). International students: Strengthening a critical resource. ACE/Rowman Littlefield.

Andrade, M. S., Evans, N., \& Hartshorn, K. (2014). Linguistic support for non-native English speakers: Higher education practices in the United States. Journal of Student Affairs Research and Practice, 51(2), 207-221.

Ascione, F. R. (1992). Enhancing children's attitudes about the humane treatment of animals: Generalization to human-directed empathy. Anthrozoos, 5, 176-191.

Baba, Y., \& Hosoda, M. (2014). Home away home: Better understanding of the role of social support in predicting cross-cultural adjustment among international students. College Student Journal, 48(1), 1-15 
Bai, J. (2016). Perceived support as a predictor of acculturative stress among international students in the United States. Journal of International Students, 6, 93-106.

Bodenhausen, G. V., \& Gawronski, B. (2013). Attitude change. In D. Reisberg (Ed.), The Oxford handbook of cognitive psychology (pp. 957-969). Oxford University Press.

Bohner, G., \& Dickel, N. (2011). Attitudes and attitude change. Annual Review of Psychology, 62, 391-417.

Brunsting, N. C., Smith, A. C., \& Zachry, C. E. (2018). An academic and cultural transition course for international students: Efficacy and socio-emotional outcomes. Journal of International Students, 8(4), 1497-1521. doi: 10.5281/zenodo.1467805

Brunsting, N., Zachry, C., \& Takeuchi, R. (2018). Predictors of undergraduate international student psychosocial adjustment to US universities: A systematic review from 2009-2018. International Journal of Intercultural Relations, 66, $22-33$.

Chavajay, P. (2013). Perceived social support among international students at a U.S. university. Psychological Reports, 112(2), 667-677.

Coleman, G. J. (2010). Educating the public: Information or persuasion? Journal of Veterinary Medical Education, 37(1), 74-82.

Creswell, J. W., \& Plano Clark, V. L. (2011). Designing and conducting mixed methods research (2nd ed.). Sage.

Deardorff, D. (2015). Intercultural competence: Mapping the future research agenda. International Journal of Intercultural Relations, 48, 3-5.

Dole, J. A., \& Sinatra, G. M. (1998). Reconceptualizing change in the cognitive construction of knowledge. Educational Psychologist, 33(2-3), 109-128.

Engberg, M. E., \& Mayhew, M. J. (2007). The influence of first-year "success" courses on student learning and democratic outcomes. Journal of College Student Development, 48(3), 241-258.

Festinger, L. (1962). Cognitive dissonance. Scientific American, 207(4), 93-106.

Frost, S. H. (1991). Fostering the critical thinking of college women through academic advising and faculty contact. Journal of College Student Development, 32(4), 359-366.

Gagne, R. M., Briggs, L. J., \& Wager, W. W. (1992). Principles of instruction (4th ed.). Harcourt Brace Jovanovich.

Glass, C. R. (2012). Educational experiences associated with international students' learning, development, and positive perceptions of campus climate. Journal of Studies in International Education, 16, 228-251.

Gómez, E., Urzúa, A., \& Glass, C. R. (2014). International student adjustment to college: Social networks, acculturation, and leisure. Journal of Park and Recreation Administration, 32(1), 7-25.

Han, S., Pistole, M. C., \& Caldwell, J. M. (2017). Acculturative stress, parental and professor attachment, and college adjustment in Asian international students. Journal of Multicultural Counseling and Development, 45, 111-126.

Hine, C. (2000). Virtual ethnography. Sage. 
Jaccard, J., \& Blanton, H. (2005). The origins and structure of behavior: Conceptualizing behavior in attitude research. In D. Albarracín, B. T. Johnson, \& M. P. Zanna (Eds.), The handbook of attitudes and attitude change (pp. 125171). Lawrence Erlbaum.

Jung, E., Hecht, M. L., \& Wadsworth, B. C. (2007). The role of identity in international students' psychological well-being in the United States: A model of depression level, identity gaps, discrimination, and acculturation. International Journal of Intercultural Relations, 31(5), 605-624.

Kamradt, T. F., \& Kamradt, E. J. (1999). Structural design for attitudinal instruction. In C. M. Reigeluth (Ed.), Instructional-design theories and models: A new paradigm of instructional theory (pp. 563-590). Lawrence Erlbaum.

King, P. M., \& Baxter Magolda, M. B. (2005). A developmental model of intercultural maturity. Journal of College Student Development, 46, 571-592.

Korobova, N., \& Starobin, S. S. (2015). A comparative study of student engagement, satisfaction, and academic success among international and American students. Journal of International Students, 5, 72-85.

Kort, B., Reilly, R., \& Picard, R. W. (2001, August). An affective model of interplay between emotions and learning: Reengineering educational pedagogy-building a learning companion. In Proceedings IEEE International Conference on Advanced Learning Technologies (pp. 43-46). IEEE Computer Society. doi: 10.1109/ICALT.2001.943850.

Kovtun, O. (2011). International student adaptation to a U.S. college: A mixed methods exploration of the impact of a specialized first-year course at a large Midwestern institution. Journal of Student Affairs Research and Practice, 48, 349-366.

Kuh, G. D., \& Hu, S. (2001). The effects of student-faculty interaction in the 1990s. The Review of Higher Education, 24(3), 309-332.

Li, J. Q., Liu, X., Wei, T., \& Lan, W. (2013). Acculturation, internet use, and psychological well-being among Chinese international students. Journal of International Students, 3, 155-166.

Li, J., Marbley, A., Bradley, L., \& Lan, W. (2016). Attitudes toward seeking professional counseling services among Chinese international students: Acculturation, ethnic identity, and English proficiency. Journal of Multicultural Counseling and Development, 44(1), 65-76.

Ligon, M., Ehlman, K., Moriello, G., \& Welleford, E. A. (2009). Oral history in the classroom: Fostering positive attitudes toward older adults and the aging process. Journal of Aging, Humanities and the Arts, 3(1), 59-72.

Longerbeam, S. D., DeStefano, T. J., \& Lixin, Y. (2013). "We cannot reach them": Chinese undergraduate student perceptions of the U.S. campus climate. Journal of Student Affairs Research and Practice, 50, 326-344.

Lowinger, R. J., Kuo, B. C. H., Song, H.-A., Mahadevan, L., Kim, E., Liao, K. Y.H., Change, C. Y., Kwon, K.-A., \& Han, S. (2016). Predictors of academic procrastination in Asian international college students. Journal of Student Affairs Research and Practice, 53, 90-104. 
Martirosyan, N. M., Hwang, E., \& Wanjohi, R. (2015). Impact of English proficiency on academic performance of international students. Journal of International Students, 5(1), 60-71.

Mesidor, J., \& Sly, K. (2016). Factors that contribute to the adjustment of international students. Journal of International Students, 6(1), 262-282.

Miles, M. B., Huberman, A. M., \& Saldaña, J. (2013). Qualitative data analysis: A methods sourcebook. Sage.

Mori, S. (Spring, 2000). Addressing the mental health concerns of international students. Journal of Counseling \& Development, 78(2), 137-144.

Mueller, C., Lim, J., \& Watson, S. L. (2017). First principles of attitudinal change: A review of principles, methods and strategies. TechTrends, 61(6), 560-569. https://doi.org/10.1007/s11528-017-0191-3

Nagda, B. A., \& Gurin, P. (2007). Intergroup dialogue: A critical-dialogic approach to learning about difference, inequality, and social justice. New Directions for Teaching and Learning, 111, 35-45.

Noddings, N. (2005). Educating citizens for global awareness. Teachers College Press.

Noddings, N. (2010). Moral education in an age of globalization. Educational Philosophy and Theory, 42, 390-396.

Pike, G. R., \& Kuh, G. D. (2006). Relationships among structural diversity, informal peer interactions and perceptions of the campus environment. Review of Higher Education, 29, 425-450.

Poyrazli, S., Kavanaugh, P. R., Baker, A., \& Al-Timimi, N. (2004). Social support and demographic correlates of acculturative stress in international students. Journal of College Counseling, 7(1), 73-82.

Rifkin, J. (2009). The empathic civilization: The race to global consciousness in a world in crisis. Tarcher-Penguin.

Schwandt, T. A. (2014). The Sage dictionary of qualitative inquiry. Sage.

Simonson, M. R. (1979). Designing instruction for attitudinal outcomes. Journal of Instructional Development, 2(3), 15-19.

Simonson, M. R., \& Maushak, N. (1996). Situated learning, instructional technology, and attitude change. In H. McLellan, (Ed.), Situated learning perspectives (pp. 225-242). Educational Technology Publications.

Sinatra, G. M., Kardash, C. M., Taasoobshirazi, G., \& Lombardi, D. (2012). Promoting attitude change and expressed willingness to take action toward climate change in college students. Instructional Science, 40(1), 1-17.

Smiljanic, I. (2017). The role of attachment, travel experiences and English proficiency in international students' acculturative stress and depressive symptoms. Journal of International Students, 7(2), 188-203.

Terenzini, P. T., \& Pascarella, E. T. (1980). Toward the validation of Tinto's model of college student attrition: A review of recent studies. Research in Higher Education, 12(3), 271-280.

Trice, A. G. (2007). Faculty perspective regarding graduate international students' isolation from host national students. International Education Journal, 8(1), $108-117$. 
Watson, S. L., Watson, W. R., Janakiraman, S., \& Richardson, J. (2017). A team of instructors' use of social presence, teaching presence, and attitudinal dissonance strategies: An animal behaviour and welfare MOOC. International Review of Research in Open and Distributed Learning, 18(2), 68-91.

Watson, S. L., Watson, W. R., \& Tay, L. (2018). The development and validation of the Attitudinal Learning Inventory (ALI): A measure of attitudinal learning and instruction. Educational Technology Research \& Development, 66, 1601-1617. https://doi.org/10.1007/s11423-018-9625-7

Van Horne, S., Lin, S., Anson, M., \& Jacobson, W. (2018). Engagement, satisfaction, and belonging of international undergraduates at U.S. research universities. Journal of International Students, 8, 351-374.

Young, T., \& Schartner, A. (2014). The effects of cross-cultural communication education on international students' adjustment and adaptation. Journal of Multilingual and Multicultural Development, 35(6), 1-16.

Zhang, J., \& Goodson, P. (2011). Predictors of international students' psychosocial adjustment to life in the United States: A systematic review. International Journal of Intercultural Relations, 35(2), 139-162.

Zhao, C., Kuh, G. D., \& Carini, R. M. (2005). A comparison of international student and American student engagement in effective educational practices. Journal of Higher Education, 76(2), 209-231.

WILliAM R. WATSON, $\mathrm{PhD}$, is an Associate Professor of Learning Design and Technology at Purdue University. His research focuses on the critical, systemic change of education to realize a personalized learning paradigm, including the application of technology such as video games, virtual environments, and learning management applications in order to facilitate personalized learning. Email: brwatson@purdue.edu

SUNNIE LEE WATSON, PhD, is an Associate Professor of Learning Design and Technology at Purdue University. Her research interest focuses on the design of information age, learner-centered education, including attitude change instruction and the integration of information-age learning technology such as MOOCs and PIES. Email: sunnieleewatson@purdue.edu

SARAH FEHRMAN, MA, is a PhD student in Learning Design and Technology at Purdue University. Her major research interests are sociocultural adjustment, online course design, and attitudinal change in cross-cultural learning. Email: sfehrman@purdue.edu

JI HYUN YU, PhD, is a Learning Experience Designer in the Center for Academic Innovation at the University of Michigan. Her research is situated at the intersection of learning experience design and data analytics, focusing on data-informed design for personalized and rigorous learning in online settings. Email: jihyunyu@umich.edu 
SHAMILA JANAKIRAMAN, MS, is a doctoral candidate in the Learning Design and Technology program in the Department of Curriculum and Instruction at Purdue University. Her research interests are in game-based learning, attitude change instruction, online teaching and learning, MOOCs, sustainability education and adult education. Specifically, her dissertation research focuses on the use of game-based learning to change attitudes in environmental sustainability. Email: sjanakir@purdue.edu 